\title{
Thermal Stability and the Matrix Induced Brittleness in a Ti-based Bulk Metallic Glass Composite
}

\author{
Jie Bai ${ }^{a}$, Jun Wang ${ }^{a *}$,Liyuan Li $i^{a}$, Hongchao Kou ${ }^{a}$, Jinshan Li $^{a}$ \\ ${ }^{a}$ State Key Laboratory of Solidification Processing, Northwestern Polytechnical University - NWPU, \\ Xi'an, 710072, China
}

Received: September 10, 2014; Revised: September 13, 2015

\begin{abstract}
Crystallization kinetics and nanocrystalline induced brittleness in an in-situ dendrites reinforced $\mathrm{Ti}_{44} \mathrm{Zr}_{20} \mathrm{Nb}_{12} \mathrm{Cu}_{5} \mathrm{Be}_{19}$ bulk metallic glass (BMG) composites were investigated. The activated energy of the present Ti-based metallic glass matrix is obtained to be about $201 \mathrm{KJ} / \mathrm{mol}$. As the annealing temperature rises, the annihilation of free volume is believed to cause the increase of hardness and the decrease of plasticity. Brittle fracture occurs after the precipitation of nanocrystalline, which can be ascribed to the formation of the microcracks in the matrix during deformation.
\end{abstract}

Keywords: bulk metallic glass, composite, thermal stability, mechanical properties

\section{Introduction}

As a kind of potential advanced engineering materials, bulk metallic glasses (BMGs) process lots of unique properties related to the special amorphous structure, such as high strength, high hardness, large elastic limit ${ }^{1,2}$. However, catastrophic brittleness always occurs in BMGs due to the highly localized deformation ${ }^{3,4}$. In recent years, In-situ dendrites reinforced BMG composites have been successfully synthesized in $\mathrm{Ti}^{-[5,6]}, \mathrm{Zr}^{[7,8]}, \mathrm{Cu}^{\left[{ }^{[9]},\right.} \mathrm{La}^{\left[{ }^{[10]}\right.}$ based BMGs, etc. The existing of these soft second phase in the amorphous matrix can effectively harmonize plastic deformation and stimulate the multiplication of shear bands by impeding over-propagation of single shear bands ${ }^{10}$. Great improvement on plasticity has been obtained in these BMG composites. However, as a metastable state in the thermodynamic, nanocrystalline has expected to take place at certain temperature in the glass matrix ${ }^{11,12}$, which will also greatly influence their properties. Up to now, the thermal stability and effects of pre-existing crystalline phase in the BMG composite are still far from clarification. Investigating the crystallization behavior of the matrix in BMG composite is very important for their extensive applications and long-term service. Therefore, thermal stability of the glass matrix and the crystalline induced brittleness in $\mathrm{Ti}_{44} \mathrm{Zr}_{20} \mathrm{Nb}_{12} \mathrm{Cu}_{5} \mathrm{Be}_{19}$ (Ti44) BMG composites were investigated in the present work. The aim of the present work is to further uncover the deformation mechanism of these in-situ BMG composites.

\section{Experimental Procedure}

The ingots of Ti-based BMG composites with the nominal composition of $\mathrm{Ti}_{44} \mathrm{Zr}_{20} \mathrm{Nb}_{12} \mathrm{Cu}_{5} \mathrm{Be}_{19}$ were prepared by arc melting elements (Ti, $\mathrm{Zr}, \mathrm{Nb}, \mathrm{Cu}, \mathrm{Be}>99.9 \%$ purity) in an argon atmosphere. Cylindrical samples with $3 \mathrm{~mm}$ in diameter and $60 \mathrm{~mm}$ in length were obtained by a copper mould casting method. Kinetics of crystallization in the amorphous

*e-mail:nwpuwj@nwpu.edu.cn matrix was studied via the differential scanning calorimetry (DSC, NETZSCH 404C) under a flowing high-purity argon gas protection at the heating rates from $5 \mathrm{~K} / \mathrm{min}$ to $40 \mathrm{~K} / \mathrm{min}$. To change the microstructure of the glass matrix, vacuum annealing treatments were performed at $653 \mathrm{~K}$, $673 \mathrm{~K}$, and $723 \mathrm{~K}$ for 15 minutes, respectively. The X-ray diffraction (DX-2700) and High-resolution transmission electron microscope (HRTEM, Tecnai G2 F30) was used to identify the struture evolution before and after annealing. The hardness was tested on the Vickers microhardness tester (Duramin-A300) with $1 \mathrm{~N}$ maxim load and the dwell period of 10s. Quasi-static tests were conducted on the MTS SANS CMT5105 universal testing machine by using rod-like samples of $\Phi 3 \mathrm{~mm} \times 6 \mathrm{~mm}$. After fracture, the fracture surfaces were observed by scanning electron microscope (SEM,VEGA3 TESCAN).

\section{Results and Discussion}

Figure 1a displays the microstructure of the present in-situ dendrites reinforced BMG composite. It can be seen that dendritic second phase (dark contrast) homogenously embeds in the continuous matrix (white contrast). The volume fraction of the second phase is about $44 \%$ by image analysis. The XRD pattern of the crystalline peaks overlapped on the broad diffuse-scattering amorphous pattern in Figure $1 \mathrm{~b}$ further confirms that the present composites consist of the $\mathrm{Ti}(\mathrm{Zr}, \mathrm{Nb})$ solution and the amorphous matrix.

DSC curves of the present BMG composite at different heat rates are shown in Figure 2. Obvious exothermal peaks associated with the crystalline behavior of the glass matrix can be observed. It's also noted that with the increase of heat rates, both the onsets of crystallization, $T_{\mathrm{x}}$ and the peak of crystallization, $T_{\mathrm{p}}$ shift from the low to the high temperature in Figure 2, indicating an obvious dynamic effect on the crystalline of the glass matrix. To evaluate the stability of the present $\mathrm{BMG}$ composite, activation energy is calculated, 
which represents the barrier potential needed to be passed when the matrix translates from the disordered to the ordered state. Namely, higher activation energy, more stable of the matrix. Here, Kissinger method ${ }^{13}$ is used to calculate the activation energy.

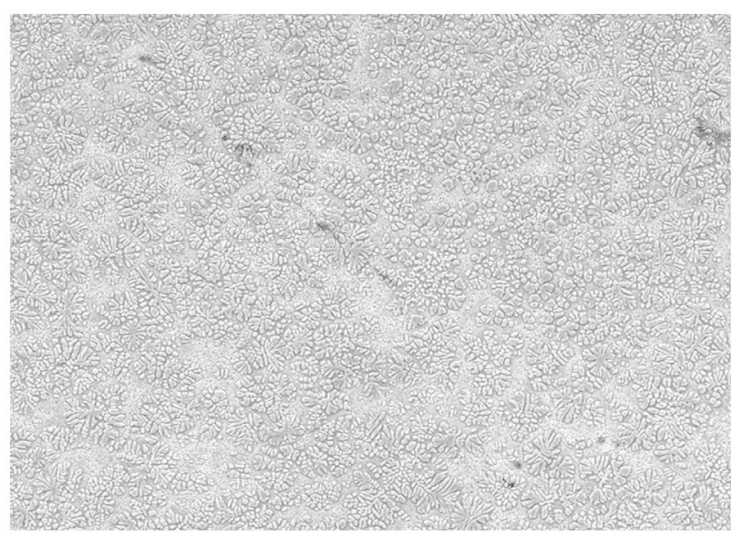

(a)

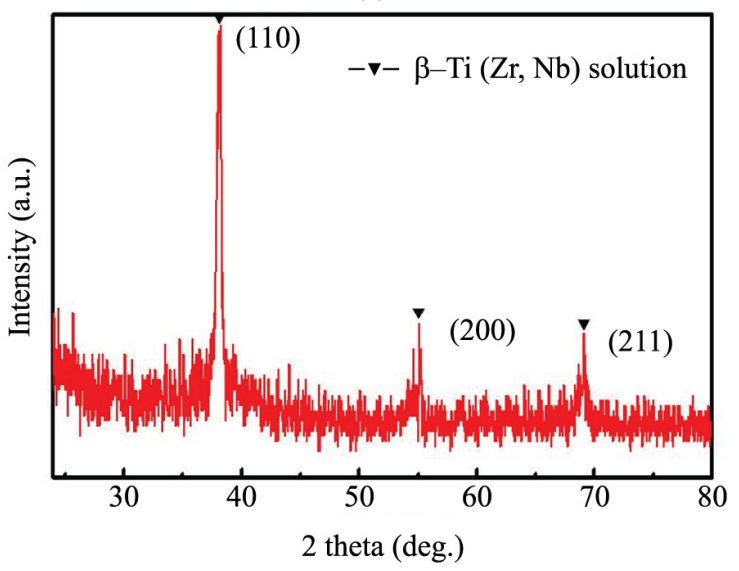

(b)

Figure 1. Microstructure of the present BMG composite (a) and the corresponding XRD pattern (b).

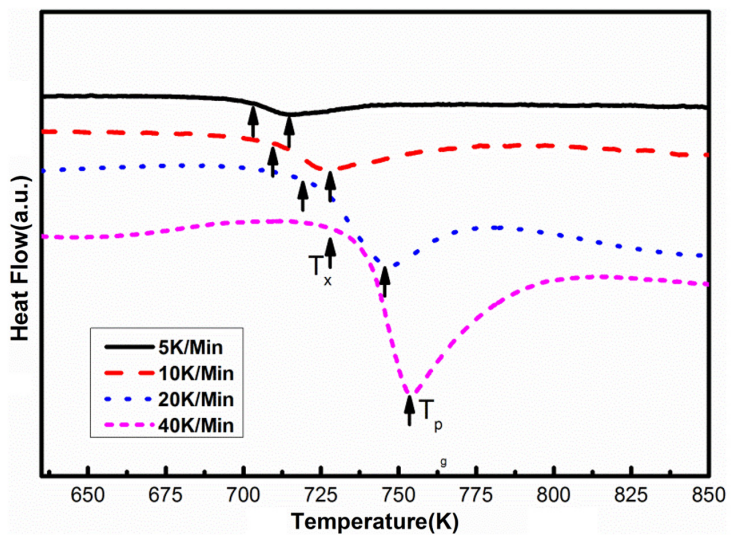

Figure 2. Continuous heating DSC curves of the present BMG composites at different heating rates. $\ln \left(\frac{\beta}{T_{p}{ }^{2}}\right)=-\frac{E_{c}}{R T_{p}}+\ln \left(\frac{A R}{E_{c}}\right)$

Where, $\beta$ and $T_{\mathrm{c}}$ represent the heat rates and characteristic temperature, respectively. $E_{\mathrm{c}}$ denotes the activation energy, $R$ is the gas constant and $A$ is a constant.

Then, the apparent crystallization activation energy, $E_{\mathrm{p}}$, for the present BMG composite can be obtained as the slope of $\ln \left(\beta / T_{p}^{2}\right)$ vs $1 / T_{p}$ curve, as shown in Figure 3.

Table 1 summarizes the activation energy of the present BMG composite and some other Ti-based monolithic BMGs. It can be obvious seen that the BMG composite has the lowest activation energy. That implies that they will be more vulnerable to suffer from crystallization. Differing from the monolithic BMGs, which is more homogenous in the structure, the precipitated dendrites in matrix increase the heterogeneity in the matrix by formation of interface between the dendrites and the matrix. These regions could provide more nucleation sites and contribute to the nanocrystalline process. Therefore, the lower activation energy of the present BMG composite could be attributed to the special structure of BMG composite. Furthermore, because of the low thermal stability of the BMG composite, it's necessary to investigate

Table 1. Activation energy of the present BMG composite and some other Ti-based monolithic BMGs.

\begin{tabular}{lc}
\hline \multicolumn{1}{c}{ Alloys } & $\boldsymbol{E}_{\mathbf{p}}(\mathbf{K J} / \mathbf{m o l})$ \\
\hline The resent BMG composite & 201 \\
$\mathrm{Ti}_{70} \mathrm{Ni}_{30}{ }^{14}$ & 316 \\
$\mathrm{Ti}_{66} \mathrm{Ni}_{33}{ }^{14}$ & 325 \\
$\mathrm{Ti}_{60} \mathrm{Ni}_{40}{ }^{14}$ & 358 \\
$\mathrm{Ti}_{64} \mathrm{Ni}_{32} \mathrm{Si}_{4}{ }^{14}$ & 384 \\
$\mathrm{Ti}_{60} \mathrm{Ni}_{30} \mathrm{Si}_{10}{ }^{14}$ & 418 \\
$\mathrm{Ti}_{56} \mathrm{Ni}_{28} 2 \mathrm{Si}_{16}{ }^{14}$ & 445 \\
$\mathrm{Ti}_{45} \mathrm{Zr}_{5} \mathrm{Ni}_{45} \mathrm{Cu}_{5}{ }^{15}$ & 380 \\
$\mathrm{Ti}_{41.5} \mathrm{Zr}_{2.5} \mathrm{Hf}_{5} \mathrm{Cu}_{42.5} \mathrm{Ni}_{7.5} \mathrm{Si}_{1}{ }^{16}$ & 284 \\
$\mathrm{Ti}_{41.5} \mathrm{Zr}_{2.5} \mathrm{Hf}_{5} \mathrm{Cu}_{37.5} \mathrm{Ni}_{7.5} \mathrm{Si}_{1} \mathrm{Sn}_{5}{ }^{16}$ & 302 \\
$\left(\mathrm{Ti}_{40} \mathrm{Zr}_{25} \mathrm{Ni}_{8} \mathrm{Cu}_{9} \mathrm{Be}_{18992} \mathrm{Nb}_{8}{ }^{17}\right.$ & 250 \\
$\mathrm{Ti}_{40} \mathrm{Zr}_{25} \mathrm{Ni}_{8} \mathrm{Cu}_{9} \mathrm{Be}_{18}{ }^{17}$ & 213 \\
\hline
\end{tabular}

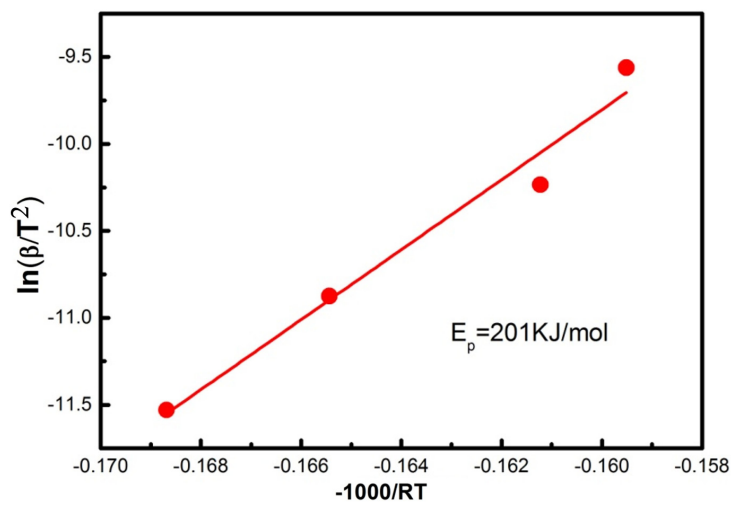

Figure 3. Plots of $\ln \left(\beta / T_{\mathrm{p}}\right)$ vs. $1 / T_{\mathrm{p}}$ of the present BMG composites. 
the effect of matrix evolution on the mechanical properties of the present BMG composite.

Figure 4 is the XRD patterns of the present BMG composites after annealing at different temperature. When annealing below the crystalline temperature $T_{\mathrm{x}}$, the XRD pattern of the present BMG composite shows no obvious differences compared with the as-casted sample. However, after annealing above $T_{\mathrm{x}}$, obvious peaks corresponding to the nanocrystalline can be clearly seen in Figure 4, implying that nanocrystallization occurs in the matrix.

To further clarify the microstructure of samples annealed at different temperature, HRTEM images are exhibited in Figure 5. As shown in Figure 5a and Figure 5b, maze-like disordered structure without any lattice fringes corresponding to nanocrystallization can be seen in both the as-casted and annealed sample at $673 \mathrm{~K}$, which indicates that the matrix still has an amorphous structure. However, lattice pattern induced by nanocrystalization can be clearly seen in sample annealed at $723 \mathrm{~K}$ in Figure 5c, in accordance with the XRD pattern in Figure 4.

Figure 6 shows the variation of the hardness with the annealing temperature. With the increase of annealing temperature, the hardness of the present $\mathrm{BMG}$ composites increases. Although no obvious differences can be observed in Figure 5a, b, the hardness of samples annealed at $673 \mathrm{~K}$ is still higher than that of as-casted sample, which can be attributed to annihilation of free volume in the matrix ${ }^{12}$. After the precipitation of nanocrystalline in the matrix at $673 \mathrm{~K}$, the hardness increases dramatically to $465 \mathrm{Hv}$.

Ambient mechanical properties of samples with different structure are shown in Figure 7. The as-casted samples possess good plasticity $(\sim 11.5 \%)$. After annealed at $653 \mathrm{~K}$ and $673 \mathrm{~K}$, the plasticity of the present BMG composites decreases to about $8.6 \%$ and $8.8 \%$, respectively. However, brittle fracture occurs after annealed at $723 \mathrm{~K}$. Mechanical properties of the present BMG composites are listed in Table 2.

Figure 8 displays the morphology of fractured samples annealed at different temperature. Both the as-casted and annealed samples below $T_{\mathrm{x}}$ show shear failure with fracture angles smaller than $45^{\circ}$, as marked in Figure $8 \mathrm{a}, \mathrm{b}$. The corresponding fracture surfaces are shown in Figure 8b, d,

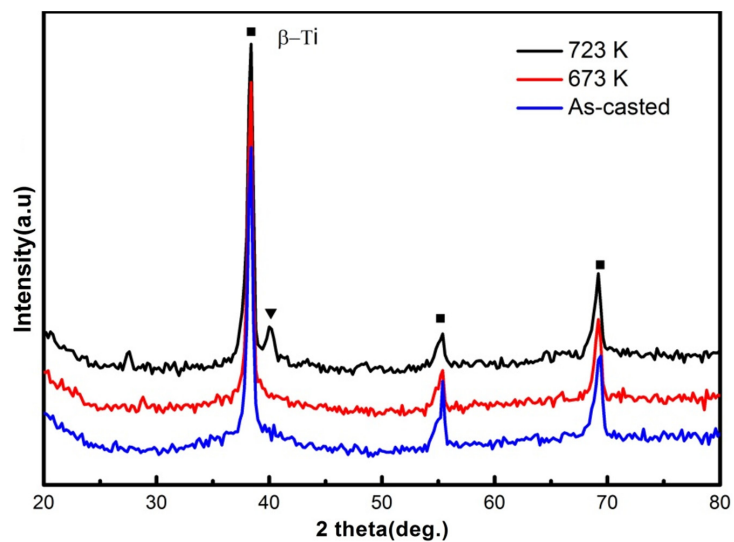

Figure 4. XRD patterns of the present BMG composite after annealing at different temperature.

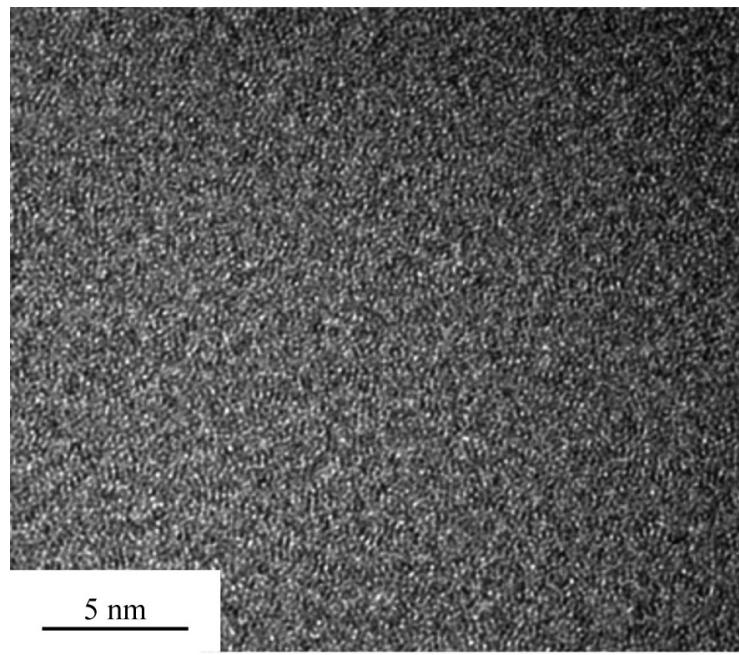

(a)

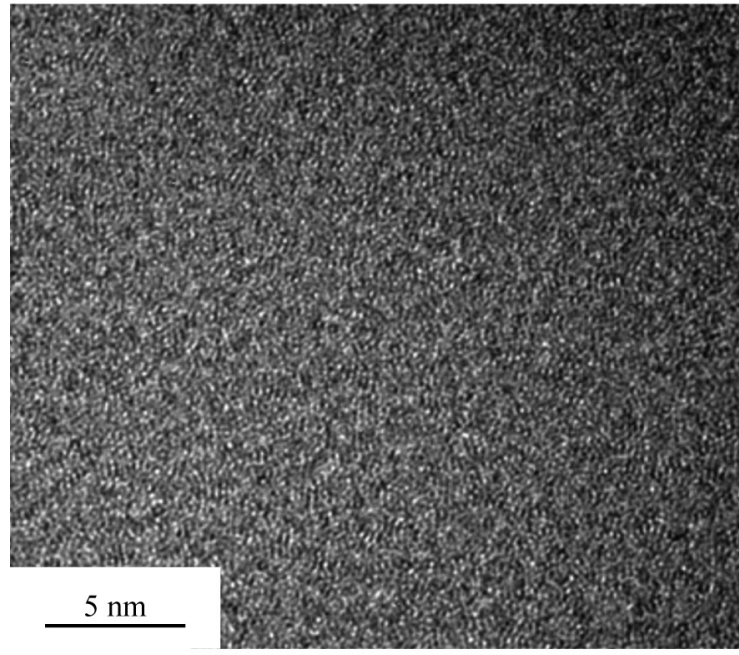

(b)

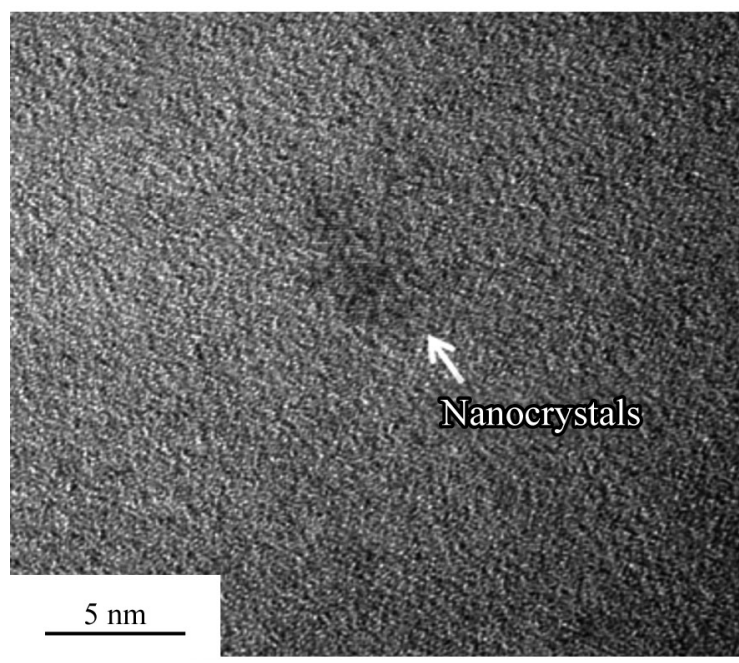

(c)

Figure 5. HRTEM images of the present BMG composite (a) as-casted, (b) annealed at $673 \mathrm{~K}$ and (c) annealed at $723 \mathrm{~K}$, respectively. 
Table 2. Summary of the mechanical properties of as-cast and annealed samples at room temperature.

\begin{tabular}{ccccc}
\hline Condition & $\boldsymbol{\sigma}_{\mathbf{0 . 2}}(\mathbf{M P a})$ & $\boldsymbol{\sigma}_{\mathbf{c}}(\mathbf{M P a})$ & $\boldsymbol{\varepsilon}(\boldsymbol{\%})$ & Hardness(HV) \\
\hline As-cast & 1433 & 1877 & 11.5 & 405 \\
$653 \mathrm{~K}$ & 1438 & 1873 & 8.6 & 424 \\
$673 \mathrm{~K}$ & 1436 & 1857 & 8.8 & 428 \\
$723 \mathrm{~K}$ & 1444 & 1692 & 3.1 & 465 \\
\hline
\end{tabular}

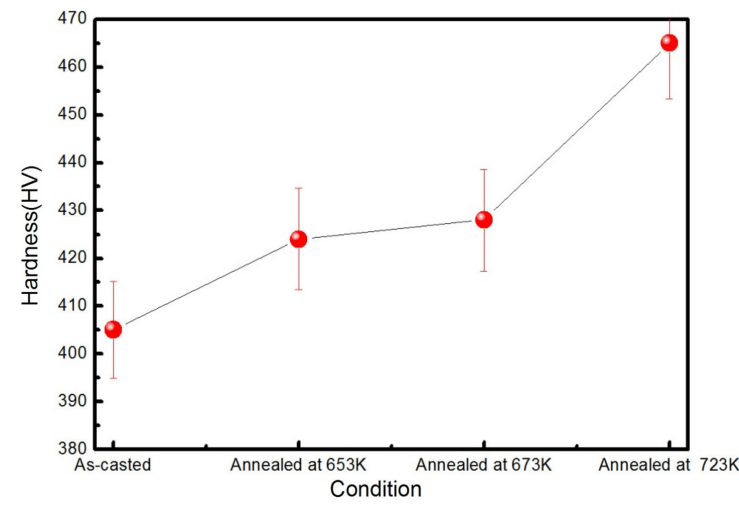

Figure 6. Variation of the hardness with the annealing temperature.

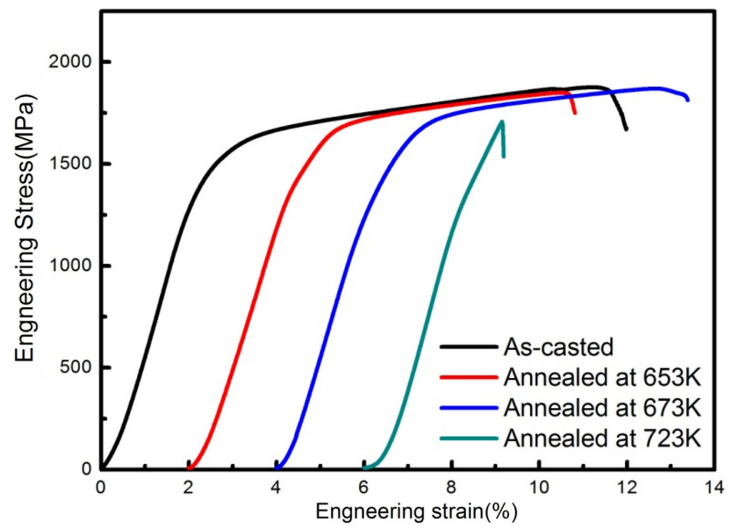

Figure 7. Mechanical properties of the as-casted and annealed samples of Ti44 BMG composites at room temperature.
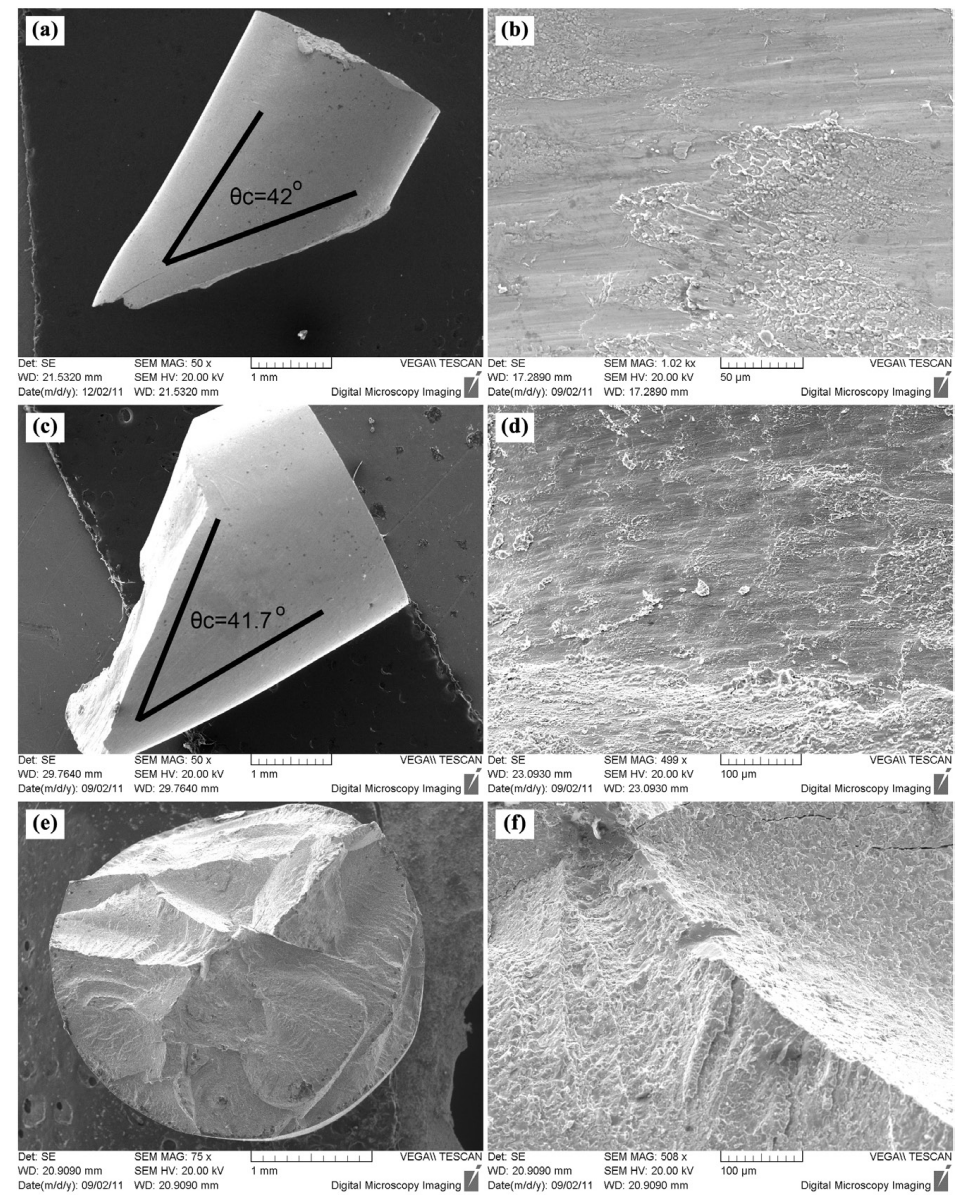

Figure 8. Fractographs of Ti44 BMG composite with different initial conditions, as casted (a and b), annealed at $673 \mathrm{~K}$ (c and d) and annealed at $723 \mathrm{~K}$ (e and $\mathrm{f}$ ). 
respectively. Lots of melting layers can also be observed on their fracture surfaces, indicating the large temperature rising due to the release of elastic energy after fracture. However, after the precipitation of nanocrystals, as shown in Figure 8e, a cleavage fracture surface can be observed. The magnified image of fracture surface (Figure $8 \mathrm{f}$ ) shows lots of micro cracks, corresponding to the brittleness of the present BMG composite after annealed at $673 \mathrm{~K}$.

For BMG composites, the plasticity will be determined by both the matrix and the dendrites. Compared with the melting point of dendrites, the annealing temperature is only about $0.2 T_{\mathrm{m}}{ }^{18}$. Thus, it's reasonable to deduce that the matrix causes the plasticity reduction of the present $\mathrm{BMG}$ composite after annealing. To illustrate the variation of mechanical properties, according to the STZ model ${ }^{19}$, the plasticity of metallic glass is initiated by stress induced cooperative rearrangement of small groups of atoms called shear transformation zones (STZs), which is believed to consist of a free volume site with immediate adjacent atoms ${ }^{20}$. Therefore, higher free volumes concentration promote the shear bands more easily to be generated in the glass matrix ${ }^{21,22}$. Further, more shear bands initiating in the matrix will results in the improvement of the whole plasticity. However, after annealing below $T_{x}$, the increase of hardness obviously indicates the annihilation of free volume. With respect to the as-casted samples, BMG composites annealed at $673 \mathrm{~K}$ involve fewer free volumes. Thus, as shown in Figure 7, lower plasticity is obtained as a consequence. When annealed above $T_{\mathrm{x}}$, the precipitation of brittle nanocrystals will further deteriorate the plasticity

\section{References}

1. Trexler MM and Thadhani NN. Mechanical properties of bulk metallic glasses. Progress in Materials Science. 2010; 55(8):759839. http://dx.doi.org/10.1016/j.pmatsci.2010.04.002.

2. Inoue A and Takeuchi A. Recent development and application products of bulk glassy alloys. Acta Materialia. 2011; 59(6):22432267. http://dx.doi.org/10.1016/j.actamat.2010.11.027.

3. Wang X, Cao QP, Chen YM, Hono K, Zhong C, Jiang QK, et al. A plastic Zr-Cu-Ag-Al bulk metallic glass. Acta Materialia. 2011; 59(3):1037-1047. http://dx.doi.org/10.1016/j.actamat.2010.10.034.

4. Tan J, Zhang Y, Stoica M, Kühn U, Mattern N, Pan FS, et al. Study of mechanical property and crystallization of a $\mathrm{ZrCoAl}$ bulk metallic glass. Intermetallics. 2011; 19(4):567-571. http:// dx.doi.org/10.1016/j.intermet.2010.12.006.

5. Hofmann DC, Suh JY, Wiest A, Lind ML, Demetriou MD and Johnson WL. Development of tough, low-density titanium-based bulk metallic glass matrix composites with tensile ductility. Proceedings of the National Academy of Sciences of the United States of America. 2008; 105(51):20136-20140. http://dx.doi. org/10.1073/pnas.0809000106. PMid:19074287.

6. Li JS, Bai J, Wang J, Kou HC, Hu R and Fu HZ. Deformation behavior of a Ti-based bulk metallic glass composite with excellent cryogenic mechanical properties. Materials \& Design. 2014; 53:737-740. http://dx.doi.org/10.1016/j.matdes.2013.07.076.

7. Hays CC, Schroers J, Johnson WL, Rathz TJ, Hyers RW, Rogers JR, et al. Vitrification and determination of the crystallization time scales of the bulk-metallic-glass-forming liquid $\mathrm{Zr}_{58.5} \mathrm{Nb}_{2.8} \mathrm{Cu}_{15.6} \mathrm{Ni}_{12.8} \mathrm{Al}_{10.3}$. Applied Physics Letters. 2001; 79(11):1605. http://dx.doi.org/10.1063/1.1398605.

8. Hofmann DC, Suh J-Y, Wiest A, Duan G, Lind M-L, Demetriou $\mathrm{MD}$, et al. Designing metallic glass matrix composites with high by generating microcracks at a rather low externally applied stress $^{23}$, as shown in Figure 8f. The fast propagation of microcracks propagates in the matrix and causes the brittle fracture of the present BMG composite.

\section{Conclusion}

Thermal stability and nanocrystalline induced brittleness of in an in situ Ti-based bulk metallic glass composite (BMG composite) were investigated. The activation energy of the present BMG composite is determined to be $201 \mathrm{KJ} / \mathrm{mol}$. With the increase of annealing below crystallization temperature, the free volume in the matrix decreases and causes the increase of hardness of present BMG composite, as well as the decrease of plasticity from $11.5 \%$ to $8.8 \%$. Brittle fracture occurs after the precipitation of nanocrystals above $T_{\mathrm{x}}$ and the fast propagation of microcracks due to nanocrystals is believed to be responsible for the cleavage fracture of the present BMG composites.

\section{Acknowledgements}

This work was supported by the Fundamental Research Fund of Northwestern Polytechnical University (JC20120203), Specialized Research Fund for the Doctoral Program of Higher Education (20136102120007) and the Program of Introducing Talents of Discipline to Universities (B08040).

toughness and tensile ductility. Nature. 2008; 451(7182): 10851089. http://dx.doi.org/10.1038/nature06598. PMid:18305540.

9. Liu Z, Li R, Liu G, Su W, Wang H, Li Y, et al. Microstructural tailoring and improvement of mechanical properties in CuZr-based bulk metallic glass composites. Acta Materialia. 2012; 60(67):3128-3139. http://dx.doi.org/10.1016/j.actamat.2012.02.017.

10. Lee ML, Li Y and Schuh CA. Effect of a controlled volume fraction of dendritic phases on tensile and compressive ductility in La-based metallic glass matrix composites. Acta Materialia. 2004; 52(14):4121-4131. http://dx.doi.org/10.1016/j. actamat.2004.05.025.

11. Mei JN, Soubeyroux JL, Blandin JJ, Li JS, Kou HC, Fu HZ, et al. Nanocrystallization-induced large room-temperature compressive plastic strain of Ti40Zr25Ni8Cu9Be18 BMG. Journal of Alloys and Compounds. 2011; 509(5):1626-1629. http://dx.doi.org/10.1016/j.jallcom.2010.11.071.

12. Song $\mathrm{M}$ and He Y. Effect of isothermal annealing on the compressive strength of a $\mathrm{ZrAlNiCuNb}$ metallic glass. Journal of Alloys and Compounds. 2011; 509(5):2606-2610. http:// dx.doi.org/10.1016/j.jallcom.2010.11.114.

13. Kissinger HE. Reaction kinetics in differential thermal analysis. Analytical Chemistry. 1957; 29(11):1702-1706. http://dx.doi. org/10.1021/ac60131a045.

14. Seeger C and Ryder PL. Kinetics of the crystallization of amorphous Ti-Ni and Ti-Ni-Si alloys. Materials Science and Engineering A. 1994; 179-180(Part 1):641-644. http://dx.doi. org/10.1016/0921-5093(94)90284-4.

15. Guo X, Louzguine D and Inoue A. Crystallization Kinetic of Ti-Zr-Ni-Cu Metallic glass. Materials Transactions. 2001; 42(11):2406-2409. http://dx.doi.org/10.2320/matertrans.42.2406. 
16. Huang YJ, Shen J, Sun JF and Yu XB. A new Ti-Zr-Hf-Cu-NiSi-Sn bulk amorphous alloy with high glass-forming ability. Journal of Alloys and Compounds. 2007; 427(1-2):171-175. http://dx.doi.org/10.1016/j.jallcom.2006.03.006.

17. Mei JN, Li JS, Kou HC, Soubeyroux JL, Fu HZ and Zhou L. Formation of Ti-Zr-Ni-Cu-Be-Nb bulk metallic glasses. Journal of Alloys and Compounds. 2009; 467(1-2):235-240. http://dx.doi.org/10.1016/j.jallcom.2007.12.066.

18. Singh PS, Narayan RL, Sen I, Hofmann DC and Ramamurty U. Effect of strain rate and temperature on the plastic deformation behaviour of a bulk metallic glass composite. Materials Science and Engineering A. 2012; 534:476-484. http://dx.doi. org/10.1016/j.msea.2011.11.096.

19. Argon AS. Plastic deformation in metallic glasses. Acta Metallurgica. 1979; 27(1):47-58. http://dx.doi.org/10.1016/00016160(79)90055-5.
20. Yang B, Liu CT and Nieh TG. Unified equation for the strength of bulk metallic glasses. Applied Physics Letters. 2006; 88(22):221911. http://dx.doi.org/10.1063/1.2206099.

21. Gu J, Song M, Ni S, Guo S and He Y. Effects of annealing on the hardness and elastic modulus of a Cu36Zr48Al8Ag8 bulk metallic glass. Materials \& Design. 2013; 47:706-710. http:// dx.doi.org/10.1016/j.matdes.2012.12.071.

22. Jiang F, Jiang MQ, Wang HF, Zhao YL, He L and Sun J. Shear transformation zone volume determining ductile-brittle transition of bulk metallic glasses. Acta Materialia. 2011; 59(5):20572068. http://dx.doi.org/10.1016/j.actamat.2010.12.006.

23. Mondal K, Ohkubo T, Toyama T, Nagai Y, Hasegawa M and Hono $\mathrm{K}$. The effect of nanocrystallization and free volume on the room temperature plasticity of Zr-based bulk metallic glasses. Acta Materialia. 2008; 56(18):5329-5339. http://dx.doi. org/10.1016/j.actamat.2008.07.012. 